\title{
Evaluation of $\mathrm{TiO}_{2}$ derived mesoporous spherical photocalysts for the oxidation of industrial waste water treatment process
}

\author{
Tae-Ho Yoon ${ }^{*}$, Kyung-Han Ko, Myung-Han Ko, and Summook Lee
}

\begin{abstract}
This paper mainly discussed the performance of photocatalysts which are prepared cation exchange resin and $\mathrm{TiCl}_{3}$ precursor via heat treatment process to enhance their photocatalytic potentials. The morphology and size of $\mathrm{TiO}_{2}$ photocatalyst was well ordered spherical shape and average diameter of $0.30 \sim 0.45 \mathrm{~mm}$ with well dispersed by $\mathrm{TiO}_{2}$ on the surface of spherical activated carbon. $\mathrm{TiO}_{2}$ supported on spherical activated carbon contains two different phases; anatase $(83 \%)$ and rutile $(17 \%)$. The $\mathrm{TiO}_{2}$ photocatalyst had high specific surface area of $1,649 \mathrm{~m}^{2} / \mathrm{g}$ and high total pore volume of $1.61 \mathrm{~cm}^{3} / \mathrm{g}$. Adsorption characteristics and photocatalytic activity of $\mathrm{TiO}_{2}$ photocatalyst were evaluated by the removal of humic acid from waste water model aqueous solution. Catalyst dosage, initial humic acid concentration, and coexisting ions have influences on the photocatalytic degradation of humic acid. The degradation of humic acid by meso-TiO2/SAC was dependent on catalyst dosage, initial its concentration. $\mathrm{TiO}_{2}$ photocatalyst has potentials for application as adsorbent and also as a photocatalyst in the removal of humic acid from groundwater and surface water.
\end{abstract}

Keywords -photocatalysts, degradation of organic compound, nano porous materials, waste water treatment

\section{Introduction}

Industrial wastewater is of global concern due to its severe effects on the environment. Compared with municipal wastewater, industrial wastewater generally contains high concentration of toxic or non-biodegradable pollutants, such as fats, oil, grease, heavy metals, phenols, and ammonia[1]. Therefore, advanced oxidation processes (AOPs), which rely on the generation of highly reactive and oxidizing hydroxyl radicals $(\cdot \mathrm{OH})$, are considered as highly competitive water treatment technologies[2].

As an important technology of AOPs, photocatalytic oxidation (PCO) has attracted increasing attention in recent

*Tae-Ho Yoon, Ph.D. (Corresponding author)

Electronics and Telecommunications Research Institute (ETRI)

South Korea

Kyung-Han Ko

CTOC Materials Co. LTD.

South Korea

Myung-Han Ko, Ph.D.

ANT21 Co. LTD.

South Korea

Sunmook Lee, Ph.D.

Korea Conformity Laboratories (KCL) years because of its excellent performance on pollutants removal, low cost, and photochemical stability and without addition of toxic chemicals $[3,4]$. Titanium dioxide $\left(\mathrm{TiO}_{2}\right)$ is widely used as a photo catalysts which degrade hydrocarbon under the existence of ultraviolet or increase of hydrophilicity of surface for self-cleaning effect in the fields of surface chemistry as bulk film coating in heterogeneous photo catalysts, because of its photo-stability, nontoxicity, low cost, and stability in water under most environmental conditions [5-7]. By these advantages, PCO has attracted increasing attention in recent years because of its excellent performance on pollutants removal, low cost, and photochemical stability and without addition of toxic chemicals $[8,9]$.

Large amount of reactive oxygen species such as hydroxyl radicals $(\cdot \mathrm{OH})$ and superoxide radical anion $\left(\cdot \mathrm{O}_{2}\right)$ are produced on the surface of $\mathrm{TiO}_{2}$ under UV light irradiation, and these reactive radicals are regarded as the major responsible species for the degradation of organic pollutants in wastewater [7-8]. The results revealed that the wastewater quality characteristics have obvious influence on the photo-degradation rate of the pollutants. PCO can also serve as a pretreatment, which can significantly enhance the biodegradability of industrial wastewater to meet requirements of the subsequent bio-treatment process $[9,10]$.

This paper deals with the characterization of photocatalyst prepared conveniently with ion exchange precursor and titanium precursor and heat-treatment process. To evaluate the performance of prepared photocatalysts, humic acid was chosen as a pollutant to be removed by adsorption and photocatalytic degradation using $\mathrm{TiO}_{2}$ photocatalysts. Humic acid mostly consists of natural organic matter, it is non-biodegradable and has color (undesirable color at concentration above $5 \mathrm{mg} / \mathrm{L}$ ), odor and also exhibits a wide range of distribution in molecular weight and size[11, 12]. For this work, we prepared in-house PCO device with $2 \mathrm{~L}$ of working volume capacity.

\section{Materials and Methods}

\section{A. Materials}

To prepare photocatalyst, cation ion-exchange resin (SAIR, Diaion SK1BH, Samyang Co. Ltd., South Korea), with a diameter range of $0.4-0.5 \mathrm{~mm}$ average particle size, was used as a support of the $\mathrm{TiO}_{2}$ photocatalyst. Titanium trichloride $\left(\mathrm{TiCl}_{3}, 20 \%\right.$, Kanto Chemical, Japan) as a $\mathrm{Ti}$ precursor was used without any additional purification process. Commercial $\mathrm{TiO}_{2}$ powder P25(Degussa Chemical, Germany) used as a reference. Humic acid was purchased from Aldrich Chemical Company, which has carbon, hydrogen, and nitrogen content of $39.44 \%, 4.74 \%$, and 
$0.79 \%$, respectively. Distilled water was used in all the experiments.

\section{B. Preparation of $\mathrm{TiO}_{2}$ photocatalyst}

The $\mathrm{TiO}_{2}$ photocatalysts was prepared via a previously described ion exchange method and heat-treatment process $[13,14]$. Titanium trichloride, distilled water and ionexchange resin were mixed in a weight ratio of $\mathrm{TiCl}_{3}: \mathrm{H}_{2} \mathrm{O}: \mathrm{SK} 1 \mathrm{BH}=1: 30: 12$ and then stirred at $150 \mathrm{rpm}$ for $1 \mathrm{hr}$ at ambient temperature. The ion-exchange resin containing $\mathrm{Ti}$ was rinsed severally with distilled water until $\mathrm{pH}$ reached 7.0, then it is dried at $110{ }^{\circ} \mathrm{C}$ for $24 \mathrm{hrs}$ in an oven. Stabilization process is performed at $300{ }^{\circ} \mathrm{C}$ for $5 \mathrm{~h}$ under atmospheric condition with a heating rate of $1{ }^{\circ} \mathrm{C} / \mathrm{min}$. The stabilized sample was carbonized at $700{ }^{\circ} \mathrm{C}$ for $10 \mathrm{~min}$ under a nitrogen conditions with flow rate of $2 \mathrm{~L} / \mathrm{min}$ with a heating rate of $3{ }^{\circ} \mathrm{C} / \mathrm{min}$ and also activated under a nitrogen/steam at $900{ }^{\circ} \mathrm{C}$ for $570 \mathrm{~min}$. The heating rate was $1{ }^{\circ} \mathrm{C} / \mathrm{min}$ up to $900{ }^{\circ} \mathrm{C}$.

\section{Characterization of $\mathrm{TiO}_{2}$ photocatalyst}

The surface morphology and size $\mathrm{TiO}_{2}$ photocatalyst was observed using scanning electron microscopy (SEM, JSM$6700 \mathrm{~F}$, JEOL), and the detailed microstructure of meso$\mathrm{TiO} 2 / \mathrm{SAC}$ was examined by field emission transmission electron microscopy (FE-TEM, Tecnai F20, FEI Co.). The crystalline phase of $\mathrm{TiO}_{2}$ photocatalyst was identified by Xray diffractometer (XRD, D/MAX-IIIB, Rigaku) employing $\mathrm{Cu} \mathrm{K}_{\alpha}$ radiation and operating at $2.0 \mathrm{~kW}$ with scanning speed of $5 \% / \mathrm{min}$ over the $2 \theta$ range $20-80^{\circ}$. The specific surface area and pore structure of $\mathrm{TiO}_{2}$ photocatalyst was determined from nitrogen adsorption-desorption isotherm at 77 K (ASAP 2010, Micromeritics Company). The specific surface area was determined by Brunauer-Emmett-Teller (BET) method and pore size distribution was analyzed using the Barrett-Joyner-Halenda (BJH) method.

\section{Adsorption isotherm estimation}

Model solution of humic acid was prepared with different concentrations of $20 \sim 100 \mathrm{ppm}$ by dissolving into distilled water. The solution was stirred for $24 \mathrm{hrs}$ and filtered through membrane filter $(0.45 \mu \mathrm{m})$. For the equilibrium experiments, $1.8 \mathrm{~g}$ of $\mathrm{TiO}_{2}$ were added into 200 $\mathrm{mL}$ of different initial concentrations of humic acid solutions. The solutions were stirred using a shaker with $25{ }^{\circ} \mathrm{C}$ and $150 \mathrm{rpm}$ and kept under dark conditions for $10 \mathrm{~h}$. The amount of humic acid adsorbed by $\mathrm{TiO}_{2}, \mathrm{q}_{\mathrm{t}}(\mathrm{mg} / \mathrm{g})$ at each time interval was calculated by following equations;

$$
q_{t}(m g / g)=\left(C_{0}-C_{t}\right) \frac{v}{m}
$$

Where, $\mathrm{C}_{0}$ : the initial concentration of humic acid (mg/L),

$\mathrm{C}_{\mathrm{t}}$ : the remaining concentration of humic acid at certain time $(\mathrm{mg} / \mathrm{L})$, respectively.

$\mathrm{V}$ : the volume of the humic acid solution (L)

$\mathrm{m}:$ the amount of $\mathrm{TiO}_{2}$ used in experiments $(\mathrm{g})$

\section{E. Photocatalytic degradation experiments}

Batch photocatalytic reaction had been performed in the $2 \mathrm{~L}$ working volume of fluidized bed photo oxidation reactor, which was made of stainless steel $(10 \mathrm{~cm}$ diameter, $40 \mathrm{~cm}$ height). A schematic diagram of the photocatalytic reactor is shown in Fig. 1. Low pressure mercury lamp (UV-C, max $=254 \mathrm{~nm}, \mathrm{G} 18 \mathrm{~T} 5 \mathrm{C}$, Light tech) used as a light source was located at the center of the reactor. $20 \mathrm{mg} / \mathrm{L}$ humic acid and appropriate amount of $\mathrm{TiO}_{2}$ put into the reactor and then air was bubbled to reaction solution through the bottom of the reactor with an air flow of $200 \mathrm{~mL} / \mathrm{min}$ to help reaction and floating of catalyst. Prior to photocatalytic experiment, sample was stirred in the dark for $10 \mathrm{~h}$ to reach an adsorption-desorption equilibrium. After stirring for $10 \mathrm{~h}$, concentration of humic acid was noted $\mathrm{C}_{0}$.

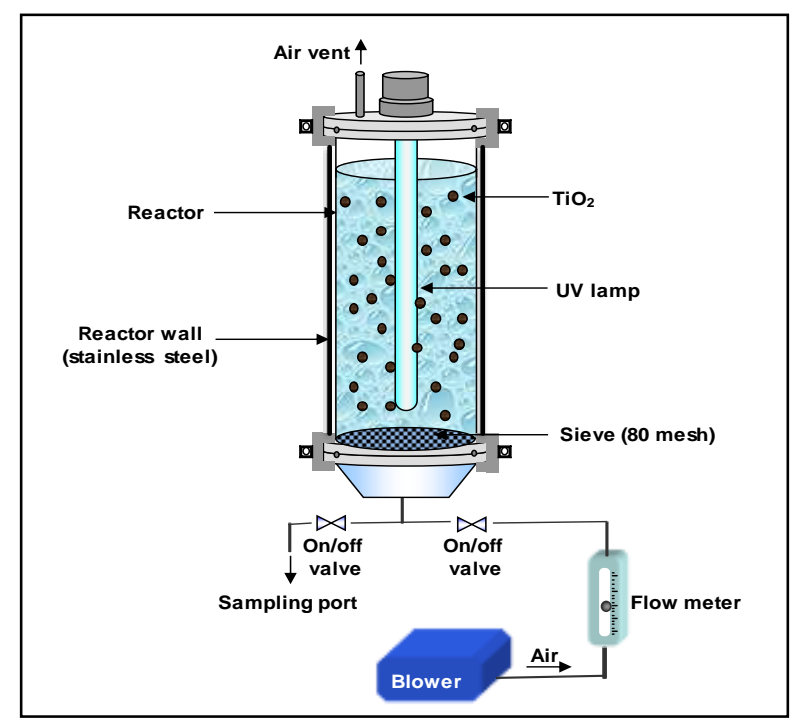

Figure 1. Schematic diagram of photocatalytic reaction experimental setup.

Every sample was collected by regular intervals for the analysis of residual humic acid concentration. To examine the effect of catalyst dosage on the photocatalytic experiment, dosage of $\mathrm{TiO}_{2}$ was varied from 6 to $12 \mathrm{~g} / \mathrm{L}$. The stability of photocatalyst was assessed through repeated use of $\mathrm{TiO}_{2}$. Repeat experiments were carried out with 20 $\mathrm{mg} / \mathrm{L}$ humic acid concentration, $9 \mathrm{~g} / \mathrm{L}$ photocatalyst, and 10 $h$ UV irradiation for cycling run. After the first photocatalytic reaction, remaining solution was replaced with fresh HA solution of $20 \mathrm{mg} / \mathrm{L}$. The used $\mathrm{TiO}_{2}$ was rinsed 5 times with distilled water for the next cycles. The above procedure was repeated for seven cycles. Blank experiments were conducted under the same conditions without photocatalyst. To compare with commercially available $\mathrm{P} 25, \mathrm{TiO}_{2}$, photocatalyst was applied as a reference. In the photocatalytic experiment using P25 $\mathrm{TiO}_{2}$, collected samples after photocatalysis were centrifuged at 13,000 rpm for $15 \mathrm{~min}$ to separate $\mathrm{P} 25 \mathrm{TiO} 2$ particles from sample solution before TOC analysis. The degradation efficiency (\%) of humic acid was calculated by Eq. (2), where $\mathrm{C}_{0}$ and $\mathrm{C}_{\mathrm{t}}$ are the equilibrium concentration of humic acid after adsorption and the remaining concentration of HA at certain time, respectively.

The concentration of humic acid was determined by UVvis spectrophotometer (Qvis 4000, Cmac). The mineralization degree was assessed by total organic carbon (TOC) analysis, performed on a TOC analyzer (Torch, 
Teledyne Tekmar). Chemical oxygen demand(COD) was also measured using COD test kit (Cmac).

Degradation efficiency $(\%)=\left(\frac{C_{0}-C_{t}}{C_{0}}\right) \times 100$

\section{Results}

\section{A. Characterization of $\mathrm{TiO}_{2}$ photocatalyst}

As shown in figure 2(a), SEM image of $\mathrm{TiO}_{2}$ shows good spherical shape with smooth surface without any defects and average diameter photocatalysts observed under SEM was in the range of $0.30 \sim 0.45 \mathrm{~mm}$ with narrow size distribution. It implies that $\mathrm{TiO}_{2}$ can be easily separated from the treated solution after the photocatalytic reaction due to their relatively large diameter compare than that of nano size of P25 photocatalysts. FE-TEM was used to obtain more detailed microstructure information and the result is presented in figure 2(b). It can be clearly seen that the $\mathrm{TiO} 2$ with ranging $10-30 \mathrm{~nm}$ was relatively well dispersed over the surface of spherical activated carbon.

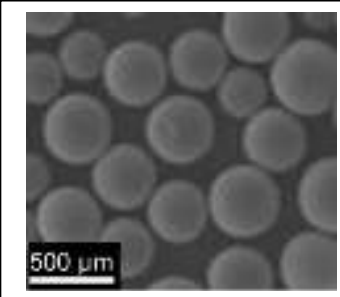

(a)

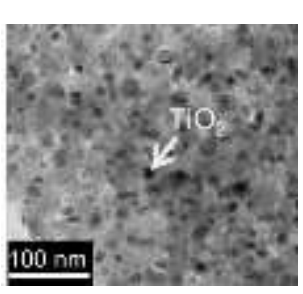

(b)
Figure 2. (a) SEM image of prepared $\mathrm{TiO}_{2}$ photocatalytsts and (b) FETEM image of $\mathrm{TiO}_{2}$ photocatalytsts.

To evaluate the crystalline structure of $\mathrm{TiO}_{2}, \quad$ XRD analysis was performed and showed results in figure 3. XRD pattern of P25 $\mathrm{TiO}_{2}$ was also presented. It can be seen that peak positions of $\mathrm{TiO}_{2}$ were similar with $\mathrm{P} 25 \mathrm{TiO}_{2}$ and exhibited mixture of anatase/rutile phases. The relative content of anatase and rutile was estimated using Spurr-

Myers equation, $\mathrm{A}(\%)=(\mathrm{IA} / \mathrm{IA}+1.265 \mathrm{IR}) \times 100$, where $\mathrm{A}$ $(\%)$ is the relative content of anatase, IA and IR are the intensities of the anatase (101) peak at $2 \theta=25.2^{\circ}$ and the rutile (110) peak at $2 \theta=27.3 \circ$. The $\mathrm{TiO}_{2}$ has a relative content of $83 \%$ for anatase and $17 \%$ for rutile. Degussa P25 $\mathrm{TiO}_{2}$, which is well known to have high photocatalytic activity, consists $78 \%$ anatase and $22 \%$ rutile. Ratio of anatase and rutile for meso-TiO2/SAC looks quite similar to that of $\mathrm{P} 25 \mathrm{TiO}_{2}$. A mixture of anatase/rutile also exhibits a higher photocatalytic activity than that of each of the pure phases.

To measure the specific surface area of $\mathrm{TiO}_{2}$ photocatalyst, BET measurement was performed. The specific surface area of $\mathrm{TiO}_{2}$ photocatalyst was found to be $1,649 \mathrm{~m}^{2} / \mathrm{g}$ (ca. 30 times higher than that of the Degussa P25 $\mathrm{TiO}_{2}$ ). This value is similar with the most widely used commercial activated carbon, (800-1500 $\left.\mathrm{m}^{2} / \mathrm{g}\right)$. The nitrogen adsorption-desorption isotherm of $\mathrm{TiO}_{2}$ photocatalyst is presented in figure 4 . The isotherm exhibits a typical IUPAC type IV with a hysteresis loop at high relative pressure of $\mathrm{P} / \mathrm{P}_{0}=0.6-1.0$, thus indicating the presence of mesopores. The ranges of pores were located at $0.8-35 \mathrm{~nm}$. It was observed that $\mathrm{TiO}_{2}$ photocatalysts showed a bimodal pore size distribution, that is, micropores with ranging from $1 \mathrm{~nm}$ to $1.6 \mathrm{~nm}$ and mesopores in the range of 5-20 $\mathrm{nm}$. The average pore size of $\mathrm{TiO}_{2}$ photocatalyst was $8.39 \mathrm{~nm}$, suggesting that mesopores in $\mathrm{TiO}_{2}$ photocatalyst are more dominant.

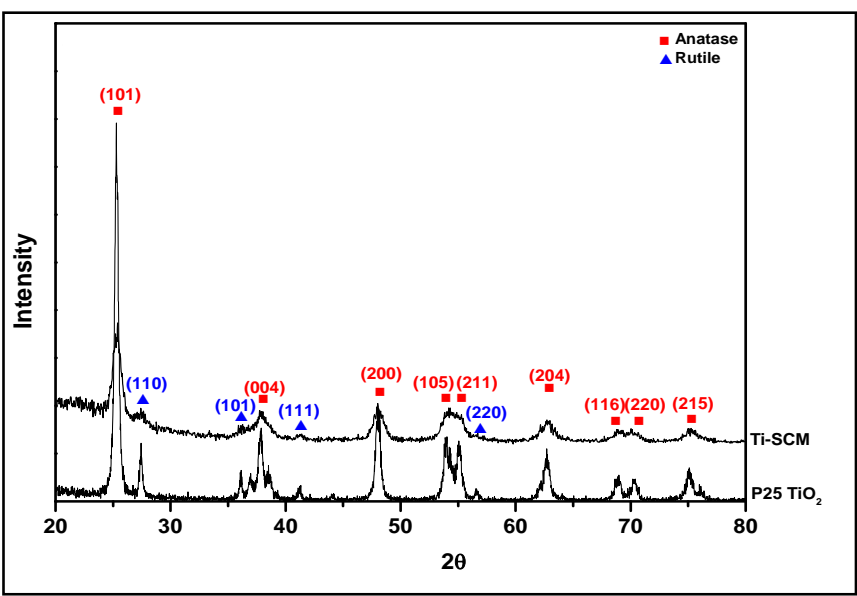

Figure 3. Comparison of XRD pattern between $\mathrm{TiO}_{2}$ photocatalyst prepared from cation exchange resin with $\mathrm{TiCl}_{3}$ and commercial $\mathrm{P} 25 \mathrm{TiO}_{2}$.

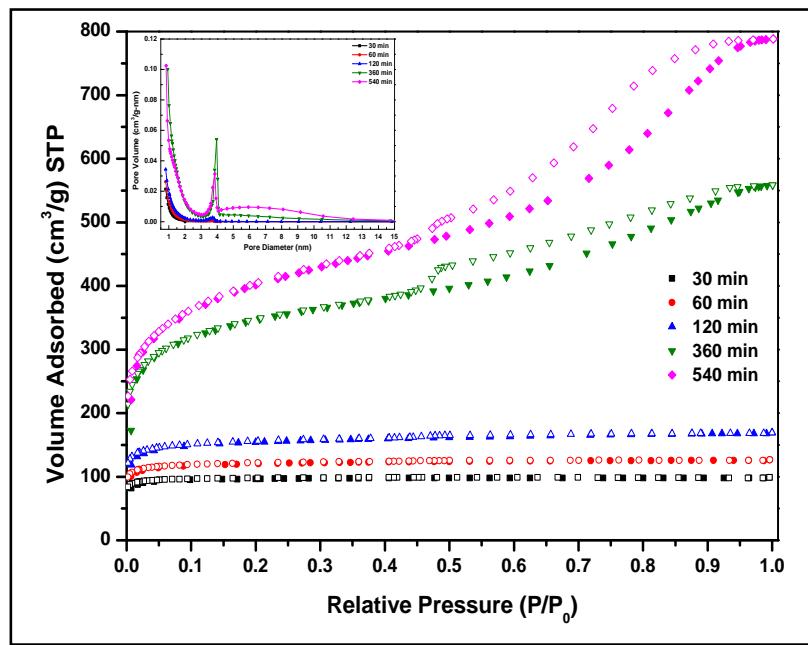

Figure 4. Nitrogen adsorption-desorption isotherm of $\mathrm{TiO}_{2}$. Inset: pore size distribution of the isotherm for $\mathrm{TiO}_{2}$ photocatalysts depending on the pyrolysis time.

\section{B. Adsorption properties of photocatalysts}

In order to evaluate adsorption characteristics of humic acid on $\mathrm{TiO}_{2}$ photocatalyst, adsorption kinetics was performed in the dark conditions varying initial concentration of humic acid in the range of $20-100 \mathrm{mg} / \mathrm{L}$ as shown in figure 5. It was found that adsorption of humic acid on $\mathrm{TiO}_{2}$ photocatalyst occurred despite that humic acid has large molecular size and equilibrium adsorption was reached almost in about 2 hrs. Spherical activated carbon has large number of adsorption sites because of their 
developed well pore structure with very large surface area. This may be supported by the existence of mesopores (pore size: $5-20 \mathrm{~nm}$ ) of $\mathrm{TiO}_{2}$ photocatalyst, as shown in inset of figure 4 .

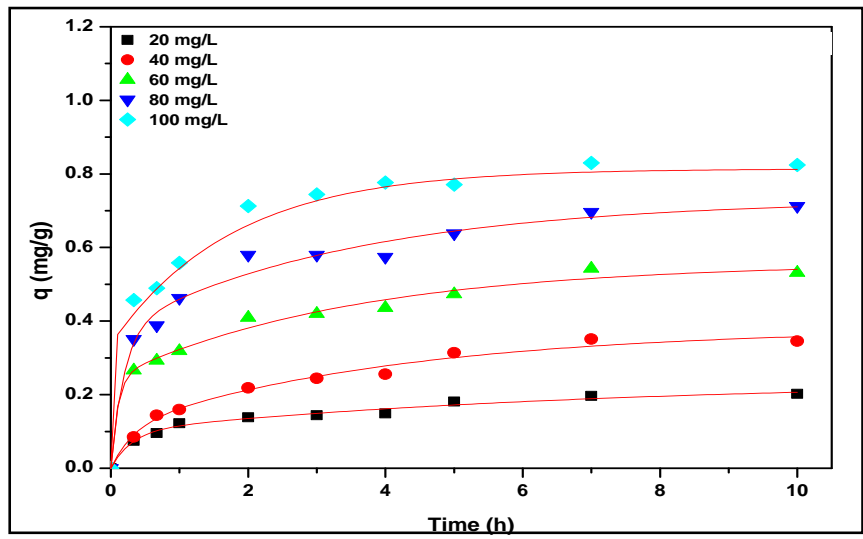

Figure 5. Adsorption kinetics of humic acid $\mathrm{TiO}_{2}$ photocatalyst at various initial concentrations (catalyst dosage $=9 \mathrm{~g} / \mathrm{L}, \mathrm{pH} 7.4$ ).

\section{Photocatalytic degradation experiments}

To evaluate effect of catalyst amounts, photocatalytic experiments were conducted with varying catalyst dosage from 6 to $12 \mathrm{~g} / \mathrm{L}$, and the results obtained were shown in figure 6. Mineralization degree of humic acid was enhanced from 60 to $80 \%$ with the increase of catalyst dosage from 6 to $9 \mathrm{~g} / \mathrm{L}$. However, TOC removal efficiency was constant when catalyst dosage was beyond $9 \mathrm{~g} / \mathrm{L}$. Increase in catalyst dosage contributes to increased number of active sites but may reduce the degradation efficiency of humic acid by blocking UV irradiation. It can be said that about a $9 \mathrm{~g} / \mathrm{L}$ dosage is suitable for practical applications from the economic point of view.

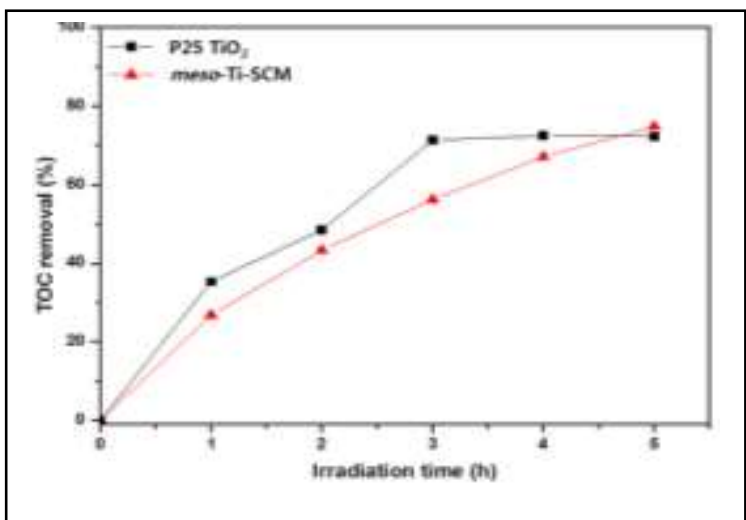

Figure 6. Effect of catalyst dosage on the photocatalytic degradation of humic acid by $\mathrm{TiO}_{2}$ photocatalyst ([Humic acid $]_{0}=20 \mathrm{mg} / \mathrm{L}, \mathrm{pH} \mathrm{7.4}$, irradiation time $=10 \mathrm{~h}$ ).

Photocatalytic experiment was carried out to assess the efficiency of $\mathrm{TiO}_{2}$ photocatalyst at different initial concentrations of humic acid in the range $20 \sim 100 \mathrm{mg} / \mathrm{L}$ since the initial concentration of pollutant is a very important parameter in water treatment. Figure 7(a) shows that the degradation efficiency of humic acid by $\mathrm{TiO}_{2}$ photocatalyst greatly decreased with increase in initial concentration of humic acid from 20 to $100 \mathrm{mg} / \mathrm{L}$.
Equilibrium concentration of TOC after reaching an adsorption-desorption equilibrium was $18.2,45.8$, and 92.5 $\mathrm{mg} / \mathrm{L}$ for 20,50 and $100 \mathrm{mg} / \mathrm{L}$ of initial HA concentration, respectively. The kinetics of HA degradation by meso$\mathrm{TiO} 2 / \mathrm{SAC}$ was analyzed using a first-order kinetic expressed in Eq. (3)

$$
\operatorname{In}\left(\frac{[T O C]_{0}}{[T O C]_{t}}\right)=k t
$$

Where, $[\mathrm{TOC}]_{0}$ : equilibrium concentration of TOC after adsorption in the dark,

$[\mathrm{TOC}]_{\mathrm{t}}$ : remaining concentration of TOC at irradiation time $\mathrm{t}$, $\mathrm{k}:$ rate constant of first-order

$\mathrm{t}$ : irradiation time

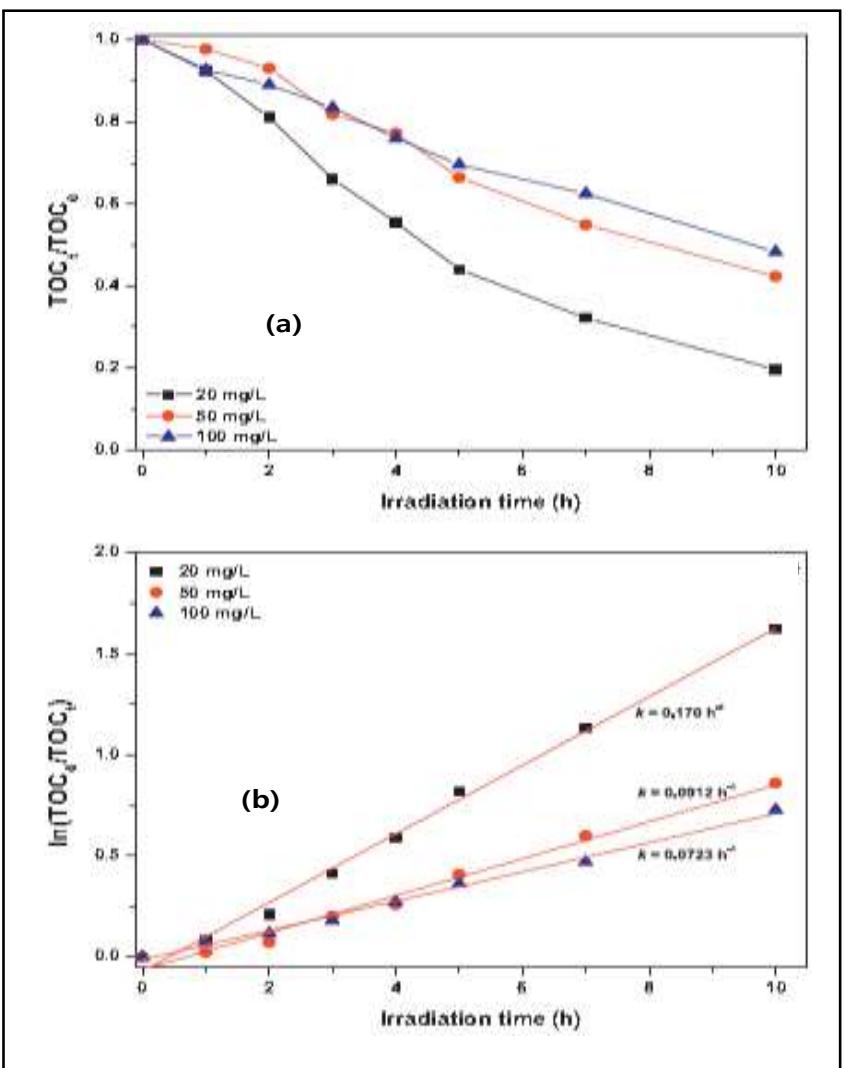

Figure 7. (a) TOC change and (b) first-order kinetics of the photocatalytic degradation of humic acid at different initial concentrations (catalyst dosage $=9 \mathrm{~g} / \mathrm{L}, \mathrm{pH} 7.4$ )

Figure $7(\mathrm{~b})$ is the plots of $\ln \left([\mathrm{TOC}]_{0} /[\mathrm{TOC}]_{\mathrm{t}}\right)$ versus $\mathrm{t}$. All the curves showed arranged well linear correlation $\left(\mathrm{R}^{2}>\right.$ 0.993), suggesting that the degradation of humic acid by $\mathrm{TiO}_{2}$ photocatalysts followed a first-order kinetic. The $\mathrm{k}$ obtained from slope of the plots was $0.170,0.0912$, and $0.0723 \mathrm{~h}^{-1}$ for 20,50 , and $100 \mathrm{mg} / \mathrm{L}$, respectively. The rate constants of TOC removal decreased with increasing initial humic acid concentration in the model solution. When the humic acid concentration increase, more humic acid molecules covering the photocatalytical active site of $\mathrm{TiO}_{2}$ photocatalyst. Thus, a number of photons which interacts with these sites decrease. As a result, hydroxyl radicals generation decrease, degradation rate of humic acid also decrease. 


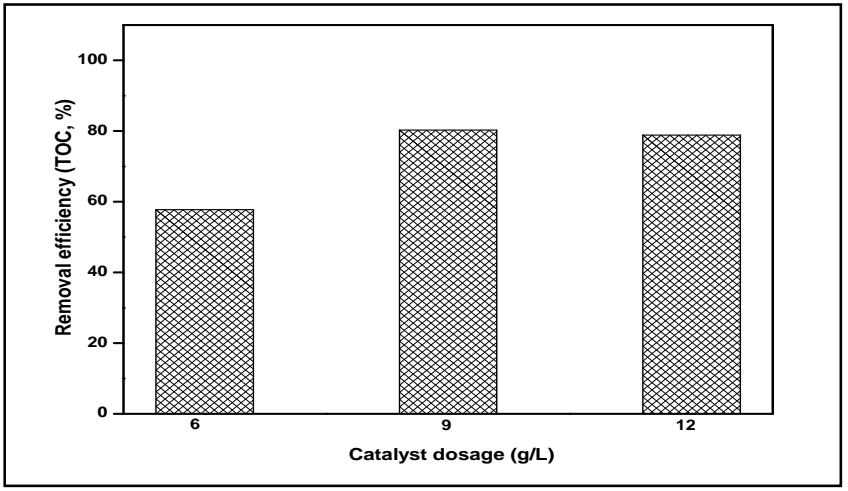

Figure 8. Comparison of $\mathrm{P} 25 \mathrm{TiO}_{2}$ and $\mathrm{TiO}_{2}$ photocatalyst on the photocatalytic degradation of humic acid ([humic acid $]_{0}=20 \mathrm{mg} / \mathrm{L}$, catalyst dosage $=9 \mathrm{~g} / \mathrm{L}\left(\mathrm{TiO}_{2}\right.$ photocatalyst $), 0.4 \mathrm{~g} / \mathrm{L}\left(\mathrm{P}^{25} \mathrm{TiO}_{2}\right), \mathrm{pH}$ 7.4).

To compare the photocatalytic efficiency between prepared $\mathrm{TiO}_{2}$ photocatalyst and commercial photocatalysts P25 $\mathrm{TiO}_{2}$, photocatalytic experiment was conducted for 20 $\mathrm{mg} / \mathrm{L}$ humic acid using $\mathrm{P} 25 \mathrm{TiO}_{2}$ of $0.4 \mathrm{~g} / \mathrm{L}$. At that time, the amount of $\mathrm{P} 25 \mathrm{TiO}_{2}$ corresponds to the titanium content (3 wt $\%$ ) of $9 \mathrm{~g} / \mathrm{L}$ of $\mathrm{TiO}_{2}$ photocatalyst. It was observed that degradation efficiency of humic acid was about $77 \%$ after UV irradiation for $5 \mathrm{~h}$ as shown in figure 8. It was similar with that of $\mathrm{TiO}_{2}$ photocatalysts. Moreover, different from P25 $\mathrm{TiO}_{2}$, prepared $\mathrm{TiO}_{2}$ photocatalyst could be easily separated from aqueous solution after use, and also the intermediates produced during photocatalytic degradation of humic acid can be also adsorbed by activated carbon and then further oxidized to avoid the secondary pollution caused by the intermediates. Also, $\mathrm{TiO}_{2}$ photocatalyst may be beneficial over $\mathrm{P} 25 \mathrm{TiO}_{2}$ for application to continuous flow systems and in the fluidized bed photoreactor system.

\section{Conclusions}

The $\mathrm{TiO}_{2}$ photocatalyst prepared from cation exchange resin and $\mathrm{TiCl}_{3}$ precursor and heat treatment process was studied for its photocatalytic potentials. The morphology and size of $\mathrm{TiO}_{2}$ photocatalyst observed by the SEM analysis was smooth spherical shape and diameter of 0.30 $\sim 0.45 \mathrm{~mm}$. The TEM analysis showed that the $\mathrm{TiO}_{2}$ was well dispersed on the surface of spherical activated carbon and the XRD analysis was confirmed that $\mathrm{TiO}_{2}$ supported on spherical activated carbon contain two different phases; anatase $(83 \%)$ and rutile $(17 \%)$. The $\mathrm{TiO}_{2}$ photocatalyst had high specific surface area of $1,649 \mathrm{~m}^{2} / \mathrm{g}$ and high total pore volume of $1.61 \mathrm{~cm}^{3} / \mathrm{g}$. It was observed that the pore size distribution curve had two distinct portions with peak pore of ca. $1.3 \mathrm{~nm}$ and $10 \mathrm{~nm}$. The pore diameter of the majority of mesopores was in the range $5 \sim 20 \mathrm{~nm}$. Adsorption characteristics and photocatalytic activity of $\mathrm{TiO}_{2}$ photocatalyst were evaluated by the removal of humic acid from waste water model aqueous solution. It was discovered that the adsorption equilibrium of humic acid on $\mathrm{TiO}_{2}$ photocatalyst was reached in about 2 hrs. Catalyst dosage, initial humic acid concentration, and coexisting ions have influences on the photocatalytic degradation of humic acid. The degradation of humic acid by meso-TiO2/SAC was dependent on catalyst dosage, initial its concentration. $\mathrm{TiO}_{2}$ photocatalyst has potentials for application as adsorbent and also as a photocatalyst in the removal of humic acid from groundwater and surface water.

\section{Acknowledgment}

This work was supported by the research fund from CTOC material Co. Ltd. and Ministry of Science, ICT and Future Planning, Korea.

\section{References}

[1] N. S. A.Mutamim, Z. Z. Noor,M. A. A. Hassan, and G. Olsson, “ Application of membrane bioreactor technology in treating high strength industrial wastewater: a performance review," Desalination, vol. 305, pp. 1-11, 2012.

[2] T. Zhang, X. Wang, and X. Zhang, "Recent progress in $\mathrm{TiO}_{2}$ mediated solar photocatalysis for industrial wastewater treatment", Int'1 J. Photoenergy, vol. 42, pp. 2640-2648, 2008.

[3] M. R. Hoffmann, S. T.Martin,W. Choi, and D.W. Bahnemann, "Environmental applications of semiconductor photocatalysis," Chemical Reviews, vol. 95, pp. 69-96, 1995.

[4] M. N. Chong, B. Jin, C. W. K. Chow, and C. Saint, "Recent developments in photocatalytic water treatment technology: a review," Water Research, vol. 44, no. 10, pp. 2997-3027, 2010.

[5] J. Shang, W. Li, and Y. F. Zhu, "Structure and photocatalytic characteristics of $\mathrm{TiO} 2$ film photocatalyst coated on stainless steel web-net", J. Molecular Catalysis A-Chemical, vol.202, pp.187-195, 2003.

[6] S. S. Madaeni, and N. Ghaemi, "Characterization of self-cleaning RO membranes coated with $\mathrm{TiO}_{2}$ particles under UV irradiation”, J. Membrane Science, vol. 303, pp. 221-218, 2007.

[7] T. Zhang,X.Yan, andD.D. Sun, "Hierarchicallymultifunctional KOMS-2/TiO2/Fe3O4 heterojunctions for the photocatalytic oxidation of humic acid under solar light irradiation," Journal of Hazardous Materials, vol. 243, pp. 302-310, 2012.

[8] Y.Kuwahara, T.Kamegawa, K.Mori, and H. Yamashita, "Design of new functional Titanium oxide-based photocatalysts for degradation of organics diluted in water and air," Current Organic Chemistry, vol. 14, , pp. 616-629, 2010.

[9] A. Fujishima, T. N. Rao, D. A. Tryk, and J. Photoch, "Titanium dioxide photocatalysis," Journal of Photochemistry and Photobiology C: Photochemistry Reviews, vol. 1, pp. 1-21, 2000.

[10] A. L. Linsebigler, G. Q. Lu, and J. T. Yates Jr., "Photocatalysis on $\mathrm{TiO}_{2}$ surfaces: principles, mechanisms, and selected results," Chemical Reviews, vol. 95, pp. 735-758, 1995.

[11] A. Imyim, and E. Prapalimrungsi, "Humic acids removal from water by aminopropyl functionalized rice husk ash", J. Hazard. Mater. vol. 184, pp. 775-781, 2010.

[12] Sh. Maghsoodloo, B. Noroozi, A. K. Haghi, and G. A. Sorial, "Consequence of chitosan treating on the adsorption of humic acid by granular activated carbon”, J. Hazard. Mater. vol. 191. pp.380-387, 2011.

[13] J. W. Yoon, M. H. Baek, J. S. Hong, C. Y. Lee, J. K. Suh, "Photocatalytic degradation of azo dye using $\mathrm{TiO}_{2}$ supported on spherical activated carbon", Kor. J. Chem. Eng., vol. 29, pp. 17221729, 2012.

[14] H. J. Jung, J. S. Hong, J. K. Suh, “A study on removal efficiency of phenol and humic acid using spherical activated carbon doped by $\mathrm{TiO}_{2}$ ", Kor. J. Chem. Eng. Vol. 28, 1882-1888, 2011. 